\title{
SILVER NANOPARTICLES INDUCED MULTIPLE ORGAN TOXICITY IN MICE
}

\author{
Osama A. Hassan ${ }^{a}$, Adel H. Saad ${ }^{b}$ and Azza H. Hamouda ${ }^{c}$ \\ ${ }^{\mathrm{a}}$ Department of Forensic Medicine \& Clinical Toxicology, ${ }^{\mathrm{b}}$ Department of \\ Physiology and ${ }^{\mathrm{c}}$ Department of Histology \& Cell Biology, Faculty of Medicine, \\ Minia University, Egypt.
}

Corresponding author: Osama A. Hassan, Forensic Medicine \& clinical Toxicology department, Faculty of Medicine, Minia University, Minia, Egypt.

E-mail: hazem13579@yahoo.com.

\begin{abstract}
Background: Silver nanoparticles (AgNPs) are considered one of the most commonly used nanoparticles due to its broad antimicrobial activity. However, the toxic effects of nanoparticles on normal cells and living organs are still not fully determined. Objectives: the present study was designed to investigate the toxicity of silver nanoparticles on liver, kidneys, brain and spleen in mice and to explore the possible mechanisms behind it. Material and Methods: 16 male mice from local strain were randomly classified into (1) control group (2) silver nanoparticles treated group; mice were orally administered AgNPs $(1 \mathrm{mg} / \mathrm{kg} /$ day) for 28 days. Biochemical analysis for serum levels of liver transaminases, urea and creatinine, lipid peroxides, reduced glutathione, superoxide dismutase, total antioxidant capacity and TNF- $\alpha$ were done in addition to histopathological examination for the four organs. Results: silver nanoparticles treated group showed significantly elevated serum levels of liver transaminases, urea and creatinine together with significant high levels of lipid peroxides and TNF- $\alpha$ with significant decrease in serum levels of reduced glutathione, superoxide dismutase and total antioxidant capacity. Histopathology of the organs revealed tissue damages in AgNPs treated group evidenced by disturbed organ architecture, congestion, increased inflammatory cells with signs of necrosis. Conclusion: administration of silver nanoparticles produced remarkable toxic effects to the liver, kidneys, brain and spleen of mice, probably via activation of oxidative stress and inflammatory processes in these organs.
\end{abstract}

Key words: Silver nanoparticles, organ toxicity, oxidative stress, inflammation.

\section{INTRODUCTION}

Nanoparticles (NPs) are present everywhere in our surrounding environment, in air, medical devices, nanotechnology structures and even our food (Kong et al., 2011).

Nanotechnology is now becoming emerging and most encouraging field for creating new applications in medicine; however, just few nanoparticles are at present being used for medical applications. Silver nanoparticles (AgNPs) are considered the most noticeable nanoproduct (Faedmaleki et al., 2016).

The antimicrobial properties of AgNPs make it widely used in biomedical and consumer products 
(Ge, 2014; Vance et al., 2015). There are various products containing AgNPs as medical devices (Dayyoub et al., 2017), food storing containers (Peters et al., 2016), wound dressing, baby bottles, house hold goods and cosmetics (Marambio-Jones and Hoek, 2010).

This wide prevalent use of AgNPs in consumer products increases the concern about the risk of potential hazards and toxicity of these nanoparticles on human health (Yarmohammadi et al., 2014). As a result, the investigations around AgNPs have been increased in the recent years (Theodorou et al., 2014).

Biomedical studies showed that AgNPs can travel along the blood stream and accumulate in different body tissues and organs making these organs susceptible for damage and altered physiological function (Park et al., 2010; Sardari et al., 2012).

However, the mechanisms of toxicity and the tissues affected by AgNPs are not completely understood (Chen et al., 2016).

Increased intracellular level of reactive oxygen species (ROS) and induction of oxidative stress together with induction of the inflammatory process is suggested to be responsible for the potential toxic effects of AgNPs (Patlolla et al., 2015).

Because of the wide spread use of AgNPs in medicine and commercial products and the possibility of their potential side effects, the present study was designed to investigate the possible toxic effects of a low dose of
AgNPs on some organs and the possible mechanisms of this toxicity via evaluating the histopathological, biochemical, inflammatory and oxidative stress biomarkers in mice.

\section{MATERIALS \&METHODS Animals:}

Sixteen male mice weighing from (17-20 g) were procured from the central animal facility of Minia University. Animals were housed at room temperature with normal light/dark cycles. All mice were provided with commercially available normal pellet diet and water ad libitum. Animals were left to acclimatize in their new environment for one week prior to the inclusion in the experimental manipulations. Experimental procedures and care of animals were carried out according to the guidelines of the Ethical Committee of Faculty of Medicine, Minia University.

\section{Drugs and chemicals:}

Silver nanospheres $20 \mathrm{~nm}$ particle size of $0.02 \mathrm{mg} / \mathrm{ml}$. in water was purchased from Sigma Aldrich Co. All other chemicals and kits used in the study were from commercially available companies.

\section{Experimental design:}

Animals were randomly divided into two main groups $(n=8)$ :

1- Control group: animals were given distilled water orally as a vehicle for the experimental period of 28 days.

2- Silver nanoparticles treated group: animals were administered AgNPs at a dose of $1 \mathrm{mg} / \mathrm{kg}$ per day by oral gavage (Park et al., 2010) 
for the experimental period of 28 days.

N.B. $\mathrm{LD}_{50}$ was done for AgNps $20 \mathrm{~nm}$ in mice by ip administration using Dixon's up-and-down method and was found to be $169.39 \pm 1.31$ $\mathrm{mg} / \mathrm{kg}$ (Elkhawass et al., 2015). In the current study we used $1 \mathrm{mg} / \mathrm{kg}$ for 28 days which equal to $1 / 169.39$ of the $\mathrm{LD}_{50}$.

At the end of the experiment, mice were anesthetized by ether after an overnight fasting, and blood was collected from the heart of animals and allowed to clot at room temperature, and then centrifuged at $3000 \mathrm{rpm}$ for $15 \mathrm{~min}$. The serum was collected, labeled and stored at - $20{ }^{\circ} \mathrm{C}$ till the time of biochemical assays. Following blood collection, liver, kidneys, spleen and brain from mice were dissected and removed, washed with cold saline and specimens from the organs were preserved in $10 \%$ formalin and sent for histopathological examination.

\section{Histological examination:}

Specimens from liver, kidney, spleen and brain tissues were fixed in $10 \%$ neutral buffered formalin solution, dehydrated in ascending grades of alcohol, and embedded in paraffin. Sections were cut with a microtome, deparaffinized with xylol, rehydrated in a graded series of ethanol, and stained with hematoxylin and eosin.

\section{Biochemical assay:}

1. Determination of serum liver transaminases level:

Serum alanine transaminase (ALT) and aspartate transaminase (AST) levels were measured by colorimetric method, following the method described by Young, (1995).

2. Determination of serum urea and creatinine level:

Serum urea was measured by enzymatic colorimetric urea kit, according to the method described by Fawcett et al., (1960).

Serum creatinine was determined using an enzymatic colorimetric creatinine kit, according to the method of Schirmeister et al., (1964).

3. Determination of serum level of lipid peroxidation products:

Plasma malondialdehyde (MDA) level, as an indicator of lipid peroxidation, was determined by colorimetric method using a commercially available kit (Biodiagnostic, Egypt) as previously described (Okhawa et al., 1979).

4. Determination of Reduced glutathione, superoxide dismutase and total antioxidant capacity:

Plasma reduced glutathione (GSH) was measured by direct colorimetric method as reported by Floreani et al., (1997).

Plasma superoxide dismutase (SOD) activity was measured by EIA (Cayman Chemical) according to the method previously reported by Ndisang \& Jadhav, (2009).

The plasma total antioxidant capacity (TAC) assay was done by EIA (Cayman Chemical) according to the method previously reported by Ndisang \& Jadhav, (2009).

5. Determination of plasma tumor necrosis factor- $\alpha$ (TNF $\alpha$ )

Plasma concentration of TNF $\alpha$ was measured by using rat TNF $\alpha$ ELISA kit (Biosource, USA) 
according to the manufacturer's protocol.

\section{Statistical analysis:}

Data were presented as mean \pm standard error of the mean (M \pm SEM). Statistical analysis was performed using Graph pad Prism 5 software and significant difference between groups was done by student's t- test with a $\mathrm{P}$ value of $\leq 0.05$ was considered statistically significant.

\section{RESULTS}

1- Effects of silver nanoparticles administration on serum liver transaminases:

Administration of AgNPs produced a significant increase in serum ALT and AST levels (52.53 $\pm \quad 5.39$ and $428.5 \pm 28.89$ respectively) compared to the control group $(21.57 \pm 1.75$ and $146.1 \pm 6.77$ respectively) (fig. 1 ).

2- Effects of silver nanoparticles administration on serum urea and creatinine:

Serum urea and creatinine levels showed a significant increase in AgNPs treated animals (77.11 \pm 6.22 and $3.279 \pm 0.13$ respectively) as compared to control non treated animals $(38.50 \pm 2.75$ and $1.125 \pm$ 0.05 respectively) ( (fig. 2).

3- Effects of silver nanoparticles administration on serum oxidative stress and inflammatory biomarkers:

Administration of AgNPs significantly increased the MDA level and TNF- $\alpha$ level $(2.825 \pm 0.30$ and $57.19 \pm 4.54$ respectively) as compared to the control non treated group $(0.5513 \pm 0.06$ and $20.29 \pm$ 2.09 respectively) (fig. 3 ).
4- Effects of silver nanoparticles administration on serum antioxidant biomarkers:

Treatment with AgNPs significantly decreased serum reduced glutathione (GSH) (7.43 \pm $0.40)$ and superoxide dismutase (SOD) level $(6.18 \pm 0.46)$ and also significantly decreased serum total antioxidant capacity (TAC) level (40.14 \pm 4.31$)$ compared to the control non treated group (10.92 \pm $0.96,11.14 \pm 0.59$ and $71.98 \pm 5.79$ respectively) (table 1).

\section{5- Results of histopathological examination: \\ Regarding liver} histopathological examination, it revealed that AgNPs treated group showed liver damage in the form of multiple foci of necrosis, fibrosis, congestion and inflammatory cells (fig. 4).

Kidney sections of AgNPs treated mice showed distorted glomeruli with widened capsular space. Capillaries are congested and tubular lining cells arerarified with vaculations and pyknotic nuclei (fig. 5) as compared to normal control kidney, denoting kidney damage.

Administration of AgNPs led to splenic damage as compared to the control non treated group in the form of ill-defined diffuse white pulp, vacuolation of cells, distorted lymphoid architecture and congestion of red pulp (fig. 6).

Neurotoxicity is demonstrated in brain sections which revealed that neurons shrink, become eosinophilic with vacuolations and dark pyknotic nuclei and the intercellular space among the neurocytes is increased in AgNPs 
treated group as compared to the control non treated group (fig. 7).

Table (1): Effects of AgNPs on serum antioxidant levels. Data are expressed as mean \pm SEM of 8 observations per group. *: Significant difference from control group, $\mathrm{P} \leq 0.05$.

\begin{tabular}{|l|c|c|c|}
\hline \multicolumn{1}{|c|}{ Parameters } & GSH(mg/dl) & SOD $(\mathbf{U} / \mathbf{m l})$ & TAC $(\boldsymbol{\mu M} / \mathbf{m g}$ protein $)$ \\
\hline Control group & & & \\
\hline AgNPs treated group & $10.92 \pm 0.96$ & $11.14 \pm 0.59$ & $71.98 \pm 5.79$ \\
& $7.43 \pm 0.40^{*}$ & $6.18 \pm 0.46^{*}$ & $40.14 \pm 4.31^{*}$ \\
& $(\mathrm{P}=0.0047)$ & $(\mathrm{P}<0.0001)$ & $(\mathrm{P}=0.0006)$ \\
\hline
\end{tabular}
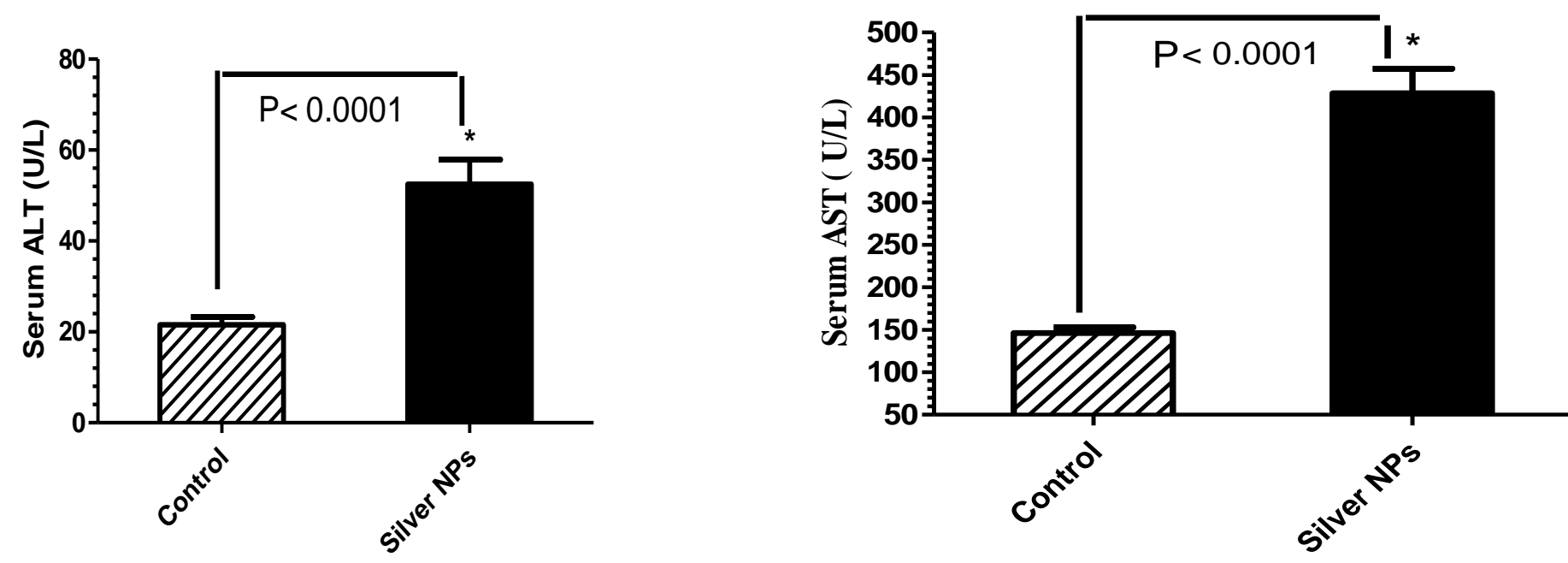

Figure 1: Effect of AgNPs on serum liver ALT and AST. Data are expressed as mean \pm SEM of 8 observations per group. *: Significant difference from control group, $\mathrm{P} \leq 0.05$. 

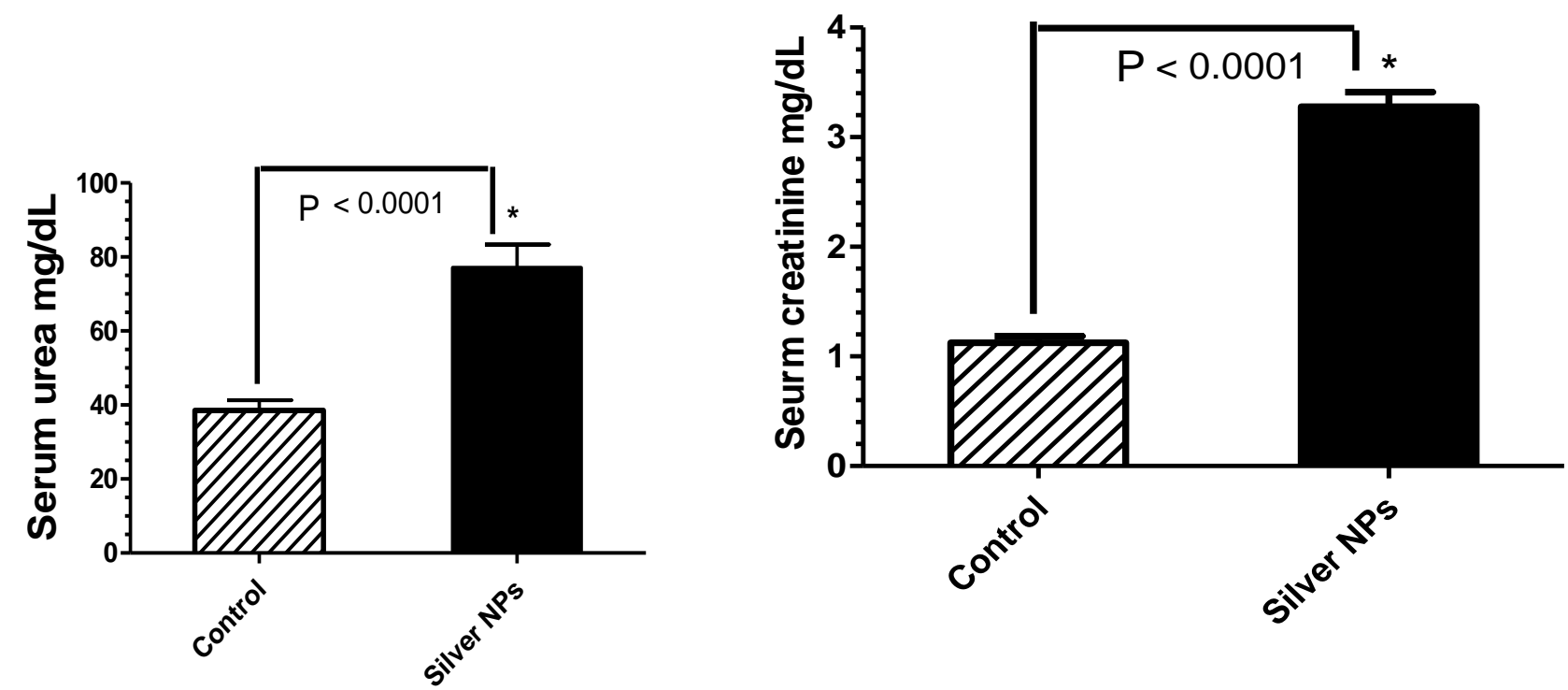

Figure 2: Effect of AgNPs on serum urea and creatinine. Data are expressed as mean \pm SEM of 8 observations per group. *: Significant difference from control group, $\mathrm{P} \leq 0.05$.
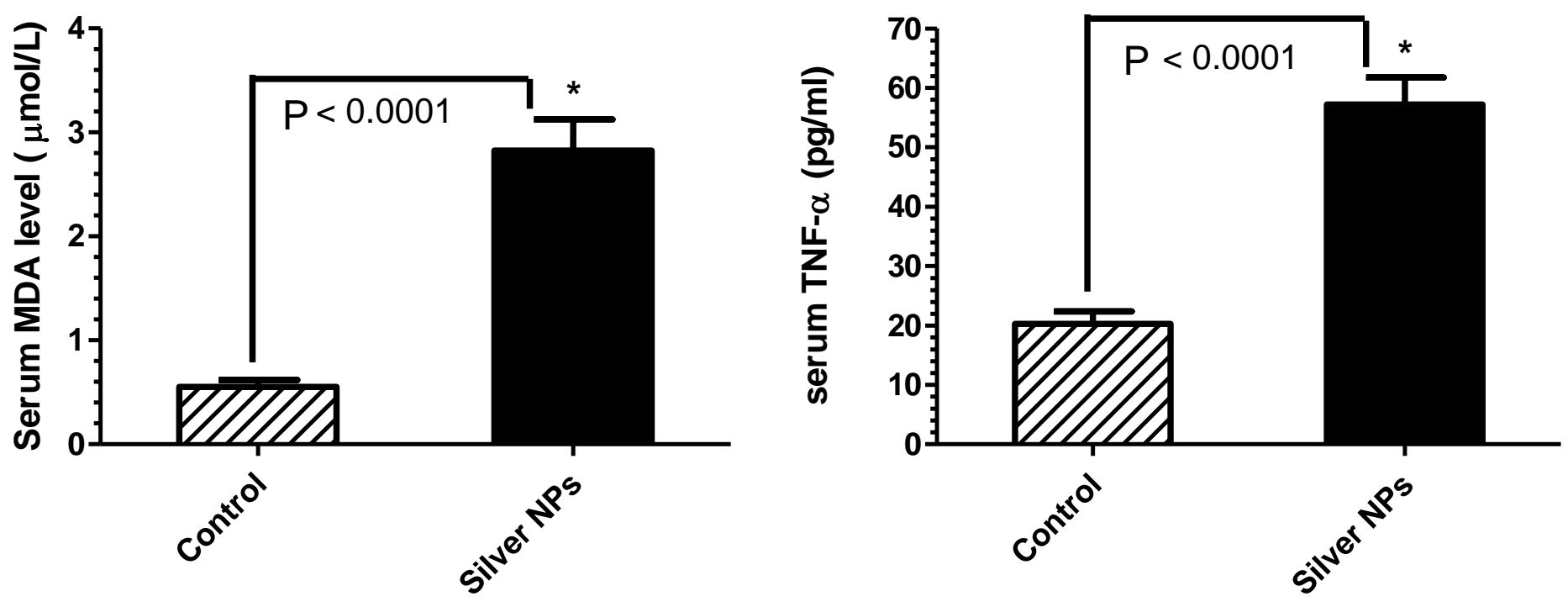

Figure 3: Effect of AgNPs on serum MDA and TNF- $\alpha$ level. Data are expressed as mean \pm SEM of 8 observations per group. *: Significant difference from control group, $\mathrm{P} \leq 0.05$. 

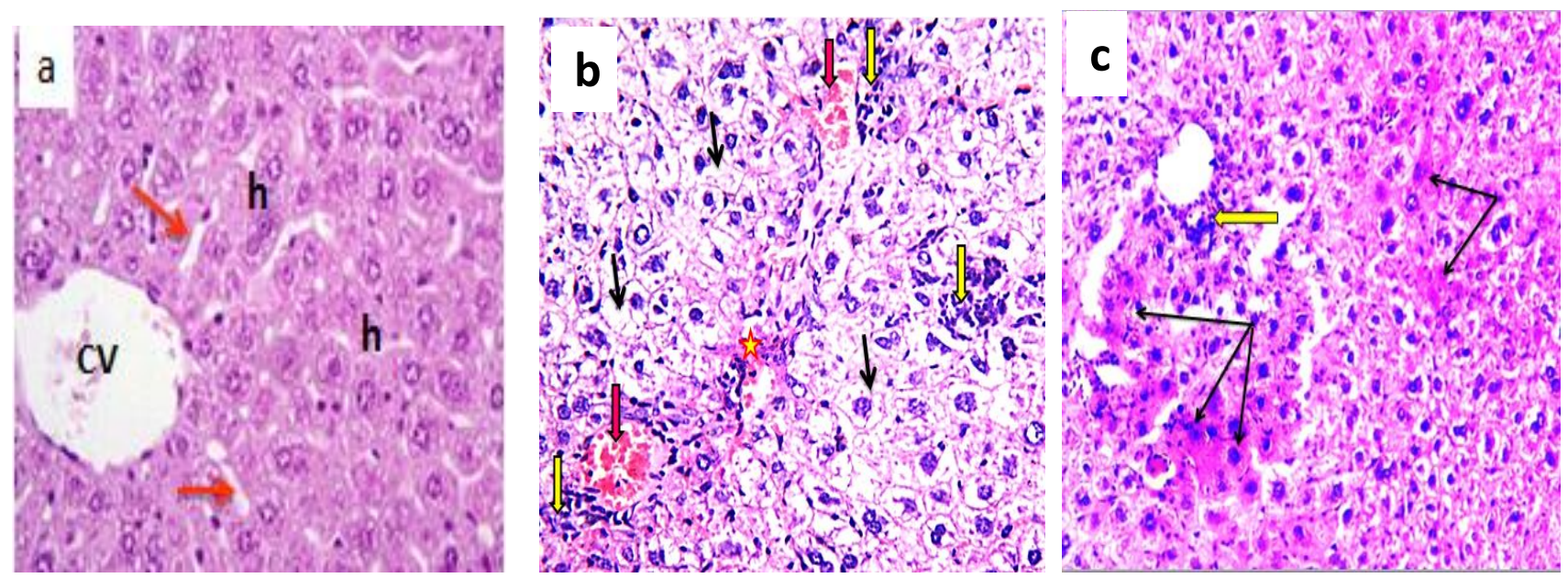

Figure 4: Photomicrographs of the liver sections: (a) Control liver section showing normal hepatic architecture; central vein (CV), hepatocytes (h) and sinusoids (red arrows). (b \& c) AgNPs treated group showing multiple foci of necrosis (black arrows), fibrosis (star), congestion (red arrows) and inflammatory cells (yellow arrows). (H\&E, $\times 400)$
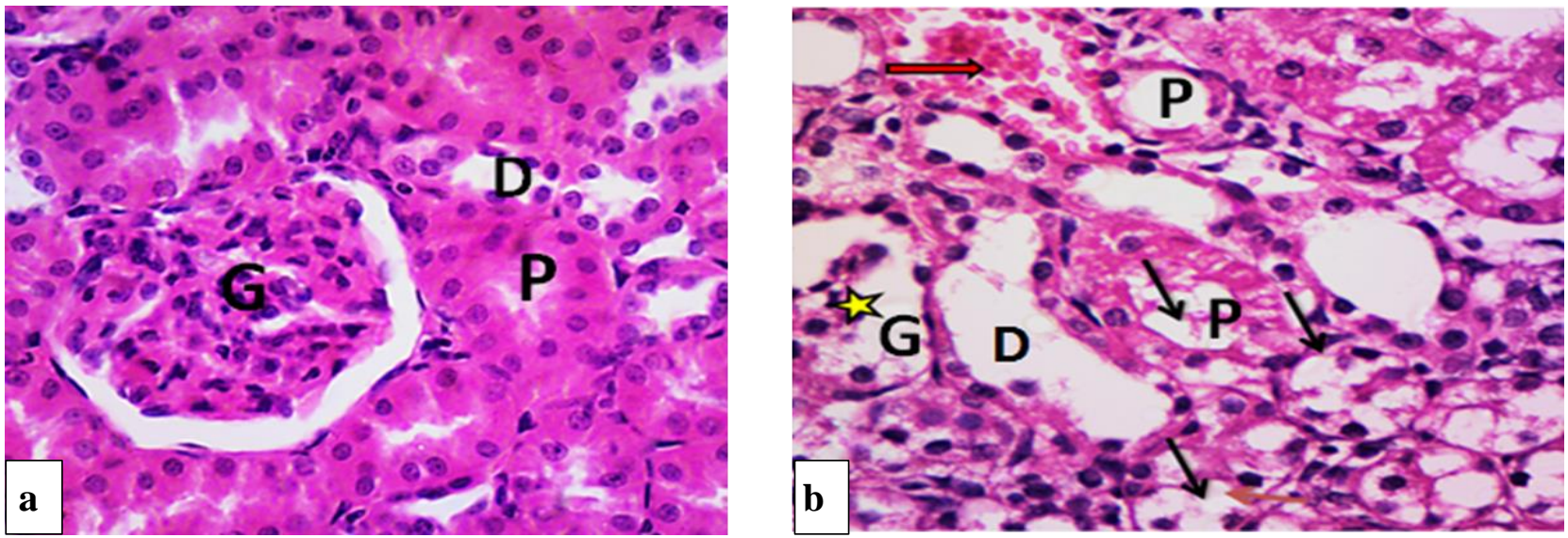

Figure 5: Photomicrographs of kidney sections (a) Control kidney showing normal glomeruli $(\mathrm{G})$, proximal convoluted tubules $(\mathrm{P})$ and distal convoluted tubules (b) Ag NPs treated group showing distorted glomeruli with widened capsular space (yellow asterisk). Capillaries are congested (red arrows) and tubular lining cells are rarified with vaculations and pyknotic nuclei (black arrows). (H\&E, $\times 400)$ 

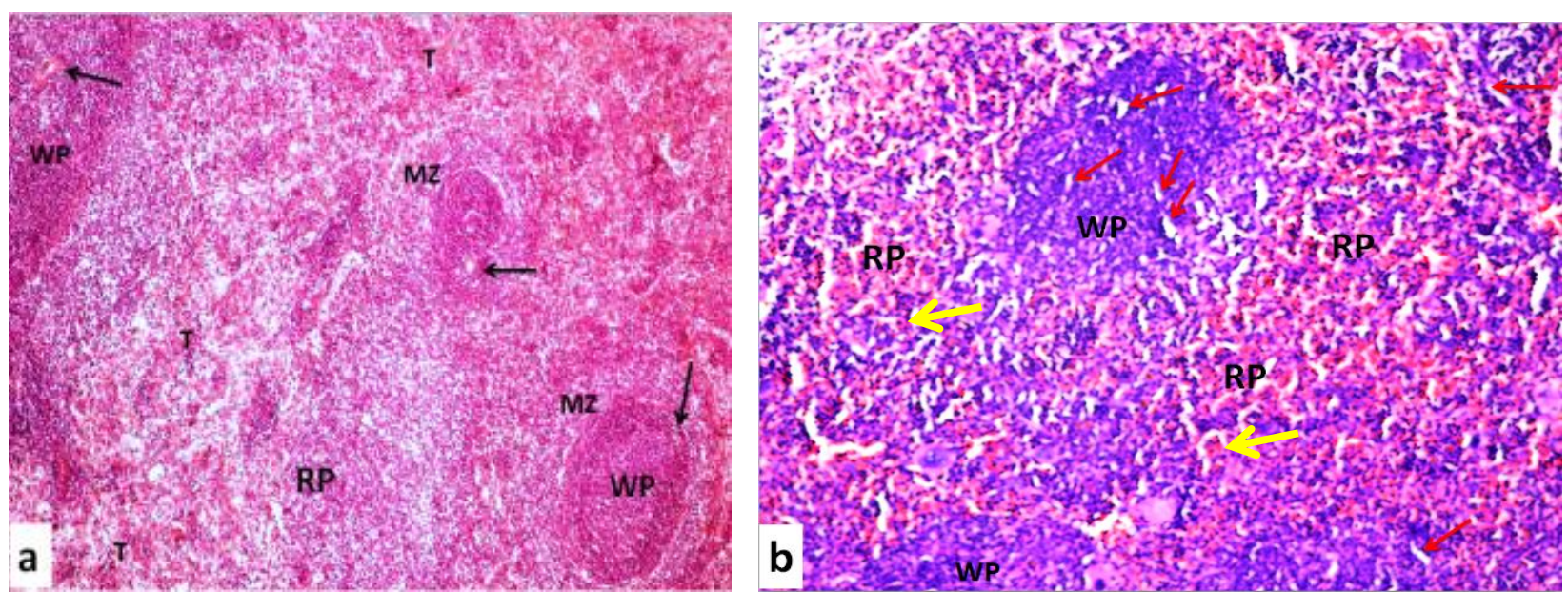

Figure 6: Photomicrographs of the spleen sections (a) control group showing normal splenic architecture with white pulp (WP), red pulp (RP) and marginal zone (MZ). (b) AgNPs treated group showing ill-defined diffuse white pulp, vacuolation of cells (red arrows), distorted lymphoid architecture and congestion of red pulp (yellow arrows). (H\&E, ×400)
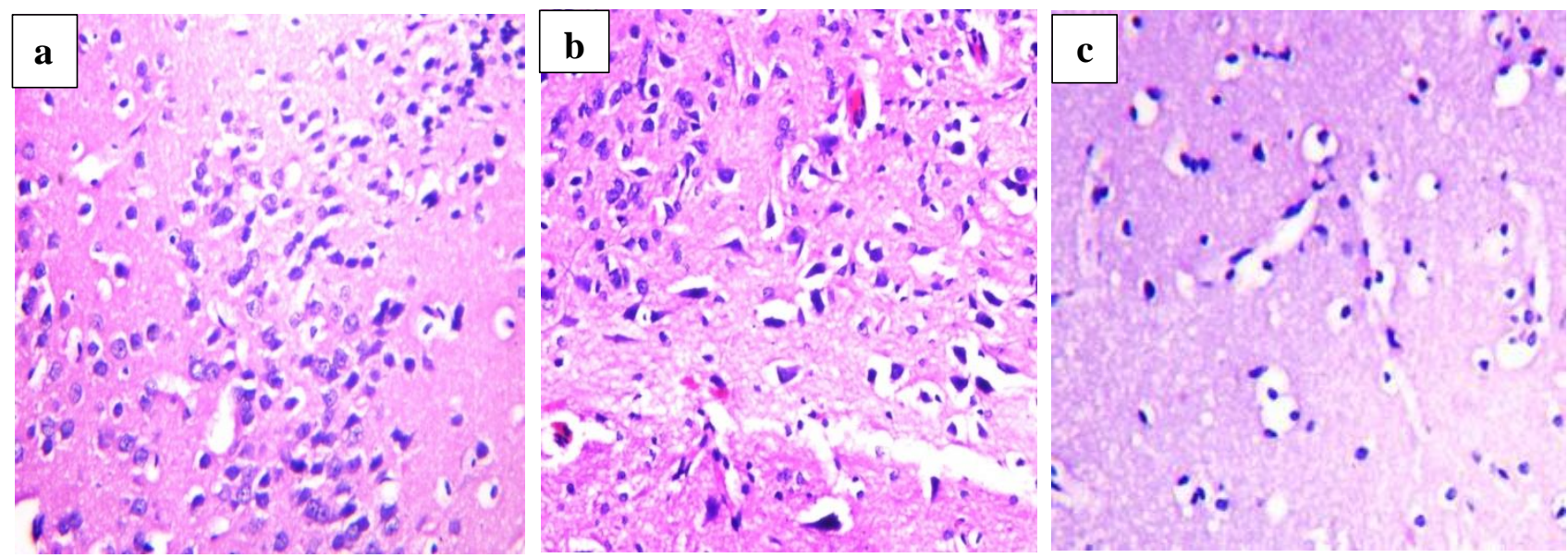

Figure 7: Photomicrographs of the brain sections: (a) control group showing normal cerebral cortex; larger cells are neurons (n) while the pink substance between cells is the neuropil (p). (b) AgNPs treated group where neurons shrink, become eosinophilic with vacuolations and dark pyknotic nuclei (black arrows). (c) The intercellular space among the neurocytes is increased. (H\&E, $\times 400)$

\section{DISCUSSION}

Antibacterial effects of silver nanoparticles are the reason of its wide uses in the medical field. Among different types of nanomaterials, AgNPs are considered the most commonly used commercial product in biomedical applications (Wang et al., 2015; Yang et al., 2012). The data about the mechanisms of toxicity of AgNPs as an important Nano medicine product after entering the circulation is not clearly understood (Chen et al., 2016). So it is important to understand AgNPs toxicity effects and investigating its possible mechanisms of toxicity.

Park et al. (2010), reported that small sized AgNPs was distributed to the liver, kidney, brain, lungs and 
testis of mice after oral administration. On the other hand, Lankveld et al. (2010), studied the kinetics of different sizes of AgNPs (20, 80 and110 nm) in rats and found that the tissue distribution of the $20 \mathrm{~nm}$ particles was mainly in the liver followed by the kidneys and spleen. Accumulation of AgNPs in certain organs has a direct relation with the organ toxicity development. So the distribution of AgNPs in different organs could give information about the target organs that may be exposed to toxicity (Mitchell et al., 2011).

In the current study we tried to investigate the potential toxic effects of a low dose of small sized AgNPs (20 nm) administered orally for 28 days on different organs including liver, kidneys, spleen and brain in mice, in addition, we tried to explore the possible mechanisms of toxicity by investigating the oxidative stress and inflammation process.

The results of the current study showed that repeated oral administration of AgNPs led to pathological changes in the liver, kidneys, spleen and brain together with elevated serum level of liver and kidney biochemical markers in mice. These results are in accordance with Moradi-Sardareh et al., (2018), who injected mice with different doses of silver nanoparticles $(0.25, \quad 0.5$ and 1 $\mathrm{mg} / \mathrm{kg}$ ) intraperitoneal for 9 days and found histopathological changes in the liver, kidney, spleen, brain and other organs, with 0.5 and $1 \mathrm{mg} / \mathrm{kg}$ doses, but contrary to our results they didn't find significant changes in the liver and kidney serum markers which may be due to the lesser period of administration. Similarly, Sardari et al., (2012), reported histopathological changes in the spleen, kidneys and liver in rats that were treated orally with 1 or $2 \mathrm{mg} / \mathrm{kg}$ of AgNPs $70 \mathrm{~nm}$ for 30 days.

Regarding hepatic effects we found that AgNPs administration led to histopathological changes in the liver in the form of multiple foci of necrosis, fibrosis, congestion and inflammatory cellular infiltration in addition to significant increase in serum level of AST and ALT when compared with the control group. These results are in agreement with the results of Ansar et al. (2017), who reported increase in AST and ALT activities and histopathological changes of the liver after intraperitoneal administration of $5 \mathrm{mg} / \mathrm{kg}$ of AgNPs in male Wistar rats.

The increase in serum level of AST and ALT together with the histopathological abnormalities of liver indicates damage of liver tissue due to repeated administration of AgNPs. Liver is a main site of accumulation of AgNPs together with spleen (Lee et al., 2013). Park et al. (2010), found that oral administration of $1 \mathrm{mg} / \mathrm{kg}$ of AgNPs in mice led to increased levels of AST and ALT in both male and female mice with increase of ALT in female mice only and didn't show histopathological changes in the liver. El Mahdy et al. (2014), demonstrated histopathological changes in the liver after intraperitoneal administration of different doses of $\operatorname{AgNPs}(1,2$ and $4 \mathrm{mg} / \mathrm{kg})$ in albino 
rats daily for 28 days. On the other hand Cho et al. (2018), showed that the intraperitoneal administration of small sized AgNPs $(10 \mathrm{~nm})$ in mice led to significant increase in AST with an increasing tendency in ALT. While Qin et al. (2017), reported that only AST was significantly increased in rats after oral administration of a 0.5 and 1 $\mathrm{mg} / \mathrm{kg}$ AgNPs daily for 28 days in addition to minor pathological changes in the liver and kidneys. Contrary to our results, Pourhamzeh et al. (2016), found that oral administration of AgNPs orally to experimental rats for 28 days didn't show considerable changes in the serum level of AST and ALT when given in different doses. These results may be due to the use of large sized nanoparticles $(78.59 \mathrm{~nm})$ than that used in our experimental study.

Regarding effects on the kidney, the obtained results of the current study showed that AgNPs led to renal damage as indicated by histopathological changes in the kidneys in the form of distorted glomeruli, congestion, vaculations and pyknotic nuclei with increased levels of serum urea and creatinine. Other previous studies also demonstrated the presence of renal damage after oral and intraperitoneal exposure to AgNPs in rats and mice (Tiwari et al., 2017; Moradi-Sardareh et al., 2018). Another route of administration was done by Wen et al. (2017), who reported increase of BUN, CR, and AST in addition to extensive damages in the kidneys, liver, spleen and thymus after intravenous administration of silver
NP in rats. In contrast to our findings regarding nephrotoxicity, Recordati et al. (2016), reported that intravenous administration of AgNPs in mice did not lead to significant pathological changes in the kidney, lung, and brain tissues. This result may be due to the use of a single dose. While Yarmohammadi et al. (2014), Observed significant increase in BUN without significant increase in serum creatinine after subacute dermal exposure to AgNPs in male mice. This result may be due to the use of another route of administration.

The findings of our current study reported that exposure to AgNPs showed histopathological changes in the spleen in the form of vacuolation of cells with ill-defined white pulp, distorted lymphoid architecture and congestion of red pulp which was consistent with previous studies (Wen et al., 2017, and Sardari et al., 2012). Moreover, Mazen et al. (2017), reported histopathological toxicity changes in the spleen of albino rats after 28 days of administration of AgNPs which was dose dependent and was attributed to oxidative stress and inflammation.

Moreover, our current study showed neurotoxicity in the form of histopathological changes in the brain including shrinkage neurons, vacuolations and dark pyknotic nuclei with increased intercellular space among the neurocytes. This result is in accordance with $\mathbf{X u}$ et al. (2015), who reported CNS damage, with intragastric low dose (1 mg/kg /day) of AgNPs in rats for 14 days, and it was attributed to the 
inflammatory effects. Previous studies have shown that intraperitoneal injection of AgNPs led to disruption of blood brain barrier (BBB) with silver being accumulated in the brain tissues and induced neurotoxicity in rats (Lebda et al., 2018). Also, in another study by Trickler et al. (2010), found that AgNPs led to increased permeability of blood brain barrier in the endothelial cells of the rat brain through a proinflammatory response. However, another study has been suggested that AgNPs crossed BBB of rats without affecting its permeability and led to neuronal toxicity in the hippocampus of rats (Dan et al., 2018).

In this study we used small sized AgNPs as previous studies have been indicated that small sized AgNPs has more organ accumulation and more toxic effects than larger nanoparticles (Beer et al., 2012). This was also confirmed by Elkhawass et al. (2015), and Cho et al. (2018), who found that smaller AgNPs (20 and 10nm) has been induced more severe symptoms than larger particles in mice after intraperitoneal administration, suggesting that the toxic effects of AgNPs has a direct relation to the size of its particles.

It has been suggested that the compounds containing nanoparticles can lead to toxic effects by increasing free radicals formation and inducing inflammatory responses (Dhasmana et al., 2017). Owing to that, in this study we tried to investigate the mechanisms of toxicity of AgNPs by evaluating the potential effects of AgNPs on oxidative stress markers by measuring the serum level of the lipid peroxides MDA and measuring the serum level of GSH, SOD and TAC with evaluation of the inflammatory response by measuring the serum level of the proinflammatory cytokine TNF- $\alpha$ in mice.

We found that exposure to AgNPs significantly increased serum level of MDA when compared to control group which may denote increased oxidative stress. This result support some other researches who reported increased serum and tissue levels of MDA after AgNPs administration in rats and mice in comparison to control non treated group (Adeyemi \& Faniyan, 2014; MoradiSardareh et al., 2018).

Moreover, our results showed that the serum level of GSH, SOD and TAC significantly reduced after repeated oral administration of AgNPs for 28 days which is consistent with the results of Ansar et al. (2017).

Increased serum level of MDA together with reduced serum levels of GSH, SOD and TAC indicates accumulation of reactive oxygen species (ROS) and oxidative damage. These results are consistent with other studies that reported ROS induction and oxidative stress has been implicated as reasons of toxicity following AgNPs administration (Kim et al., 2014; Fu et al., 2014; Patlolla et al., 2015; Skalska et al., 2016).

Our results showed that the serum level of the proinflammatory cytokine TNF- $\alpha$ was significantly 
increased when compared with the control group, indicating enhancement of the inflammatory process. The increased inflammatory response found in our study supports the results of other previous studies of Park et al. (2010) and Tiwari et al. (2017), on mice and rats.

Taking all our findings together we assume that cytotoxicity due to silver nanoparticles in our experiment is attributed to be occurred through oxidative stress and inflammation as shown by reduction of serum levels of GSH, SOD and TAC with increased serum level of the MDA and increased serum level of the proinflammatory cytokine TNF- $\alpha$.

\section{CONCLUSION}

We concluded that, repeated oral administration of small sized AgNPs $(20 \mathrm{~nm})$ were found to have a remarkable toxicity on different organs as liver, kidneys, spleen and brain in mice and the possible mechanisms of their toxicity is attributed to the free radical production with stimulation of oxidative stress and inflammatory responses.

\section{RECOMMENDATIONS}

- Silver nanoparticles must be used with caution.

- Further studies about the protection against AgNPs toxicity must be done.

- Periodic checkup for those individuals who are more prone to the risk of exposure to AgNPs.

\section{REFERENCES}

Adeyemi, O.S. and Faniyan, T.O. (2014): Antioxidant status of rats administered silver nanoparticles orally. Journal of Taibah University Medical Sciences, 9 (3): 182-186.

Ansar, S.; Alshehri, S.M.; Abudawood, M.; Hamed, S.S. and Ahamad, T. (2017): Antioxidant and hepatoprotective role of selenium against silver nanoparticles. Int J Nanomedicine, 12:7789-7797.

Beer, C.; Foldbjerg, R.; Hayashi, Y.; Sutherland, D.S. and Autrup, H. (2012): Toxicity of silver nanoparticles - nanoparticle or silver ion? Toxicol Lett, 208(3): 286-292.

Chen, R.; Zhao, L.; Bai, R.; Liu, Y.; Han, L.; Xu, Z. et al. (2016): Silver nanoparticles induced oxidative and endoplasmic reticulum stresses in mouse tissues: implications for the development of acute toxicity after intravenous administration. Toxicol. Res, 5(2): 602-608.

Cho, Y.M.; Mizuta, Y.; Akagi, J.I.; Toyoda, T.; Sone, M. and Ogawa, K. (2018): Sizedependent acute toxicity of silver nanoparticles in mice. $\mathrm{J}$ Toxicol Pathol, 31(1): 73-80.

Dan, M.; Wen, H.; Shao, A. and Xu, L. (2018): Silver Nanoparticle Exposure Induces Neurotoxicity in the Rat Hippocampus Without Increasing the Blood-Brain Barrier Permeability. J Biomed Nanotechnol, 14(7): 1330-1338. 
Dayyoub, E; Frant, M.; Pinnapireddy, S.R.; Liefeith, K. and Bakowsky, U. (2017): Antibacterial and antiEncrustation Biodegradable Polymer Coating for Urinary Catheter. International journal of Pharmaceutics, 531(1): 205214.

Dhasmana A, Firdaus S, Singh KP, Raza S, Jamal QMS, Kesari KK et al. Nanoparticles: Applications, Toxicology and Safety Aspects. In: Kesari K. (eds), Perspectives in Environmental Science and Engineering. Springer Cham, 2017; 47-70.

Elkhawass, E.A.; Mohallal, M.E. and Soliman, M.F.M. (2015): Acute toxicity of different sizes of silver nanoparticles intraperitoneally injected in $\mathrm{Balb} / \mathrm{C}$ mice using two toxicological methods. Int $\mathrm{J}$ Pharm Pharm Sci, 7(2): 94-99.

El Mahdy, M.M.; Salah Eldin, T.A.; Aly, H.S.; Mohammed, F.F. and Shaalan, M.I. (2014): Evaluation of hepatotoxic and genotoxic potential of silver nanoparticles in albino rats. Exp Toxicol Pathol, 67(1): 21-9.

Faedmaleki, F.; Shirazi, F.H.; Ejtemaeimehr, S.; Anjarani, S.; Salarian, A.A. Ahmadi Ashtiani, H. et al. (2016): Study of Silymarin and Vitamin E Protective Effects on Silver Nanoparticle Toxicity on Mice Liver Primary Cell Culture. Acta Med Iran, 54(2): 85-95.

Fawcett, J.K. and Soctt J.E. (1960): A rapid and precise method for the determination of urea. J Clinical pathology, 13: 156-159.

Floreani, M.; Petrone, M.; Debetto, P. and Palatini, $P$. (1997): A comparison Between Different Methods for the Determination of Reduced and Oxidized Glutathione in Mammalian Tissues. Free Radical Research, 26: 449-455.

Fu, P.P.; Xia, Q.; Hwang, H.M.; Ray, P.C. and Yu, H. (2014): Mechanisms of nanotoxicity: generation of reactive oxygen species. Journal of food and drug analysis, 22(1):64-75.

Ge, L.; Li, Q.; Wang, M.; Ouyang, J.; Li, X. and Xing, M.M. (2014): Nanosilver particles in medical applications: synthesis, performance and toxicity. Int $\mathbf{J}$ Nanomed, 9: 2399-2407.

Kim, S.H.; Ko, J.W.; Koh, S.K.; Lee, I.C.; Son, J.M.; Moon, C. et al. (2014): Silver nanoparticles induce apoptotic cell death in cultured cerebral cortical neurons. Mol Cell Toxicol, 10:173-179.

Kong, B.; Seog, J.H.; Graham, L.M. and Lee, S.P. (2011): Experimental considerations on the cytotoxicity of nanoparticles. Nanomedicine, 6 : 929-941.

Lankveld, D.P.; Oomen, A.G.; Krystek. P.; Neigh, A.; Troost-de Jong, A.; Noorlander, C.W. et al. (2010): The kinetics of the tissue distribution of silver nanoparticles of different sizes. Biomaterials, 31: 8350-8361

Lebda, M.; Sadek. K.M. Tohamy, H.G.; Abouzed, T.K.; Shukry, 
M.; Umerzawa, M. et al. (2018): Potential role of $\alpha$-lipoic acid and Ginko biloba against silver nanoparticles-induced neuronal apoptosis and bloodbrain barrier impairments in rats. Life Sci, 212: 251-260.

Lee, Y.; Kim, P.; Yoon, J.; Lee, B.; Choi, K.; Kil, K.H. et al. (2013): Serum kinetics, distribution and excretion of silver in rabbits following 28 days after a single intravenous injection of silver nanoparticles. Nanotoxicology, 7(6): 11201130.

Marambio-Jones, C. and Hoek, E.M.V. (2010): A review of the antibacterial effects of silver nanomaterials and potential implications for human health and the environment. $\mathrm{J}$ Nanopart. Res., 12 (5): 1531155.

Mazen, N.F.; Saleh, E.Z.; Mahmoud, A.A. and Shaalan, A.A. (2017): Histological and immunohistochemical study on the potential toxicity of sliver nanoparticles on the structure of the spleen in adult male albino rats. The Egyptian journal of Histology, 40(3): 374387.

Mitchell, L.A.; De Iuliis, G.N. and Aitken, R.J. (2011): The TUNEL assay consistently underestimates DNA damage in human spermatozoa and is influenced by DNA compaction and cell vitality: development of an improved methodology. Int. j. Androl, 34(1):2-13.

Moradi-Sardareh, H.; Basir, H.R.G.; Hassan, Z.M.; Davoudi. M.; Amidi, F. and Paknejad, M. (2018): Toxicity of silver nanoparticles on different tissues of $\mathrm{Balb} / \mathrm{C}$ mice. Life Sci., 211: 81-90.

Ndisang, J.F. and Jadhav A. (2009): Heme oxygenase system enhances insulin sensitivity and glucose metabolism in streptozotocininduced diabetes. Am J Physiol Endocrinol Metab, 296: 829 841.

Okhawa, H.; Ohishi, N. and Yagi, K. (1979): Assay for lipid peroxides in animal tissue by thiobarbituric acid reaction. Anal Chem, 95: 351-358.

Park, E.J.; Bae, E.; Yi, J.; Kim, Y.; Choi, K.; Lee, S.H. et al. (2010): Repeated-dose toxicity and inflammatory responses in mice by oral administration of silver nanoparticles. Environ Toxicol Pharmacol, 30: 162-8.

Patlolla, A.K.; Hackett, D. and Tchounwou, P.B. (2015): Silver nanoparticles-induced oxidative stress-dependent toxicity in Sprague-Dawley rats. Mol Cell Biochem, 399 (1-2): 257-268.

Peters, R.J.B.; Bouwmeester, H.; Gottardo, S.; Amenta, V.; Arena, M.; Brandhoff, P. et al. (2016): Nanomaterials for Products and Application in Agriculture, Feed and Food. Trends in Food Science and Technology, 54: 155-164.

Pourhamzeh, M.; Mahmoudian, Z.G.; Saidijam, M.; Asari, M.J. and Alizadeh, Z. (2016): The Effect of Silver Nanoparticles on the Biochemical Parameters of Liver Function in Serum, and 
the Expression of Caspase-3 in the Liver Tissues of Male Rats. Avicenna J Med Biochem, 4(2): e35557.

Qin, G.; Tang, S.; Li, S.; Lu, H.; Wang, Y.; Zhao, P. et al. (2017): Toxicological evaluation of silver nanoparticles and silver nitrate in rats following 28 days of repeated oral exposure. Environ Toxicol, 32(2): 609-618.

Recordati, C.; De, M.M.; Bianchessi, S., Argentiere, S., Cella, C., Mattiello, S., et al (2016): Tissue distribution and acute toxicity of silver after single intravenous administration in mice: nanospecific and size-dependent effects. Part Fibre Toxicol, 13:12.

Sardari, R.R.; Zarchi, S.R.; Talebi, A.; Nasri.,S.; Imani, S.; Khoradmehr, A. et al. (2012): Toxicological effects of silver nanoparticles in rats. Afr. J. Microbiol. Res, 6(27): 55875593.

Schirmeister, J.; Willmann, H.; Kiefer, H. and Hallauer, W. (1964): For and against the usefulness of endogenous creatinine clearance in functional kidney diagnosis. Dtsch med Wochenschr, 89: 1640-1647.

Skalska, J.; Dąbrowska-Bouta, B. and Strużyńska, L. (2016): Oxidative stress in rat brain but not in liver following oral administration of a low dose of nanoparticulate silver. Food Chem Toxicol., 97: 307-315.

Theodorou, I.G.; Ryan, M.P.; Tetley, T.D. and Porter,
(2014): A.E. Inhalation of silver nanomaterials-Seeing the risk. Int. J. Mol. Sci, 15 (12): 2393623974.

Tiwari, R.; Singh, R.D.; Khan, H.; Gangopadhyay, S.; Mittal, S.; Singh, V. et al. (2017): Oral Subchronic Exposure to Silver Nanoparticles Causes Renal Damage through Apoptotic Impairment and Necrotic Cell Death. Nanotoxicology, 11(5): 671-686.

Trickler, W.J.; Lantz,

S.M.; Murdock,

R.C.; Schrand,

A.M.; Robinson,

B.L.; Newport, G.D. et al. (2010): Silver nanoparticle induced blood-brain barrier inflammation and increased permeability in primary rat brain microvessel endothelial cells. Toxicol Sci, 118(1): 16070 .

Vance, M.E.; Kuiken, T.; Vejerano, E.P.; McGinnis, S.P.; Hochella, M.F.; Rejeski, D. et al. (2015): Nanotechnology in the Real World: Redeveloping the Nanomaterial Consumer Products Inventory. Beilstein Journal of Nanotechnology, 6 (1): 1769-1780.

Wang, L.; Zhang, T.; Li, P.; Huang, W.; Tang, J.; Wang, P. et al. (2015): Use of synchrotron radiation-analytical techniques to reveal chemical origin of silver-nanoparticle cytotoxicity. ACS Nano, 9(6): 6532-6547.

Wen, H.; Dan, M.; Yang, Y.; Lyu, J.; Sho, A. and Cheng, X. et al. (2017): Acute toxicity and 
genotoxicity of silver nanoparticle in rats. PLoS One, 12 (9). E0185554.

Xu, L.; Shao, A.; Zhao, Y.; Wang, Z.; Zhang, C.; Sun, Y. et al. (2015): Neurotoxicity of Silver Nanoparticles in Rat Brain After Intragastric Exposure. Journal of nanoscience and nanotechnology, 15(6): 421523.

Yang, X.; Liu, X.; Lu, H.; Zhang, X.; Ma, L; Gao, R. et al. (2012): Real time investigation of acute toxicity of $\mathrm{ZnO}$ nanoparticles on human lung epithelia with hopping probe ion conductance microscopy. Chem. Res. Toxicol, 25 (2): 297-304.

Yarmohammadi, P.; Arabi, M. and Yarmohammadi, $P$. (2014): Subacute dermal toxicity investigation of nanosilver on serum chemical biomarkers in male mice. Nanomed J, 1(4): 285-291.

Young DS. Effects of Drugs on Clinical Laboratory Tests, 4th ed. AACC Press, Washington 1995; 3-16. 


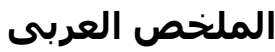

جزيئات الفضة متناهية الصغر (النانوية) تسببت فى سمية على أعضاء متعددة فى الجرذان

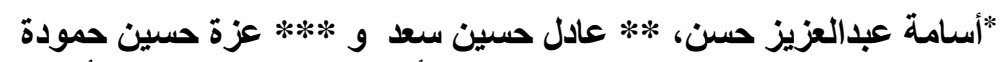

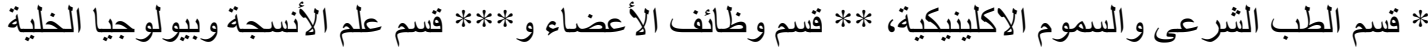
كلية الطب - جامعة المنيا

المقدمة: جزيئات الفضة المتناهية الصغر (النانوية) واحدة من الجزيئات المتناهية الصغر الأكثر استخدامًا بسبب الهيب

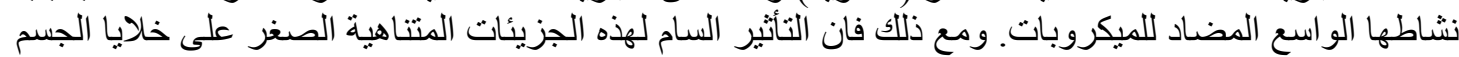

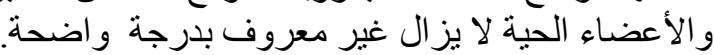

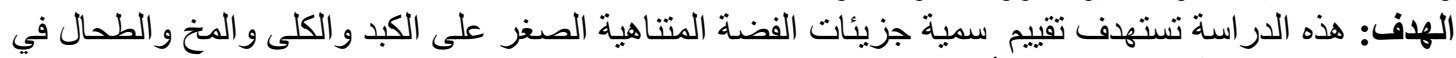

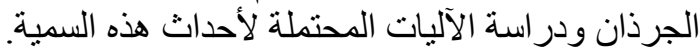

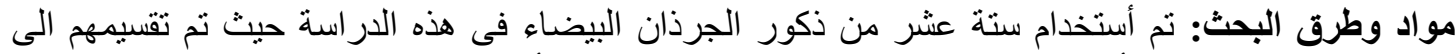

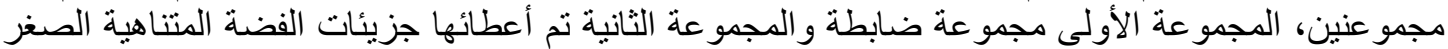

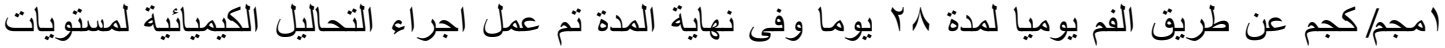

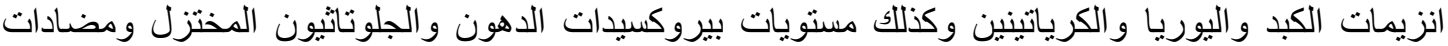

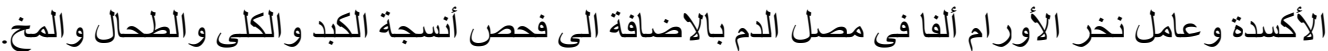

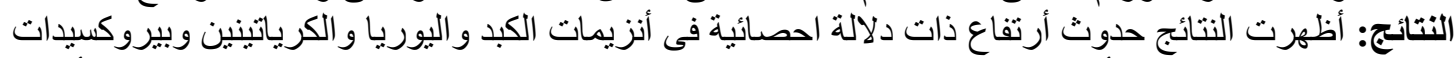

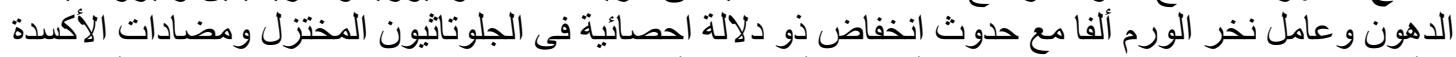

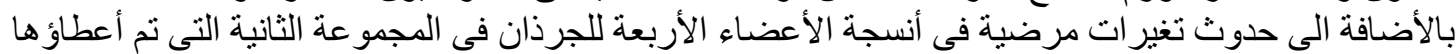

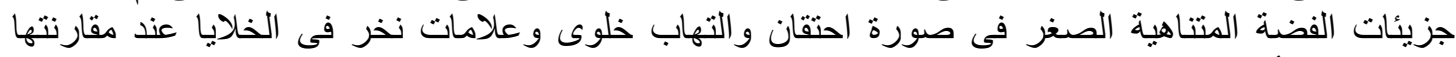

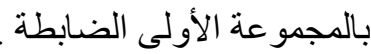
الخلاصة: تشير هذه النتائج الى أن جزيئات الفضة المتناهية الصغر أحدثت تغيرات مرضية ملحوظة على أنسجة

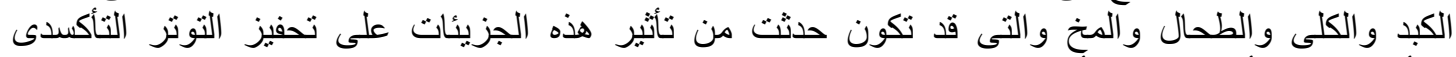
و الألتهابات فى أنسجة هذه الأعضاء. 